\title{
Intended Use of the National Nursing and Midwifery Digital Health Capability Framework
}

\author{
Leanna WOODS ${ }^{\text {al }}$, Elizabeth CUMMINGS ${ }^{\text {b,c }}$, Naomi DOBROFF d,e, \\ Shelley NOWLAN ${ }^{\text {f }}$, Helen ALMOND g,h , Paula PROCTER ${ }^{\mathrm{i}}$, Angela RYAN ${ }^{\mathrm{a}}$, \\ Meredith MAKEHAM ${ }^{\mathrm{a}, \mathrm{j}}$, Ken GRIFFIN ${ }^{\mathrm{k}}$, Julie REEVES ${ }^{1}$ and Louise SCHAPER ${ }^{\mathrm{b}}$ \\ ${ }^{a}$ Australian Digital Health Agency, Sydney, Australia \\ ${ }^{b}$ Australasian Institute of Digital Health, Melbourne, Australia \\ ${ }^{c}$ University of Tasmania, Hobart, Australia \\ ${ }^{d}$ Australian College of Nursing, Canberra, Australia \\ ${ }^{e}$ Monash Health, Melbourne, Australia \\ ${ }^{f}$ Clinical Excellence Queensland, Brisbane, Australia \\ ${ }^{g}$ Digital Health Cooperative Research Centre, Sydney, Australia \\ ${ }^{h}$ Swinburne University of Technology, Melbourne, Australia \\ ${ }^{i}$ Sheffield Hallam University, Sheffield, United Kingdom \\ ${ }^{j}$ University of Sydney, Sydney, Australia \\ ${ }^{k}$ Australian Primary Health Care Nurses Association, Melbourne, Australia \\ ${ }^{l}$ Australian Nursing and Midwifery Federation, Melbourne, Australia
}

\begin{abstract}
To realise the benefits of digital health, the health workforce needs to evolve, adapt and develop their digital proficiency. As the largest workforce in health, nurses and midwives are well positioned to lead as an agile digital healthcare workforce. The objective of this work is to describe how individual nurses and midwives, organisations and education providers could use the newly developed National Nursing and Midwifery Digital Health Capability Framework to build digital health capability. The paper concludes with an international perspective on the framework.
\end{abstract}

Keywords. digital health, health workforce, capability framework, nursing, midwifery, implementation

\section{Introduction}

The digitalisation of Australian healthcare settings requires the health workforce to evolve, adapt and build their digital proficiency. This encompasses capability, skills and attitude to operate in a technology-enabled environment [1]. Additionally, the health workforce is increasingly encountering healthcare consumers who expect their healthcare team to be digitally proficient. When implemented correctly, digital health can enhance patient safety and quality, drive workflow and bring cost efficiencies $[2,3]$.

\footnotetext{
${ }^{1}$ Corresponding Author, Leanna Woods, Australian Digital Health Agency, Level 25, 175 Liverpool St, Sydney, NSW, Australia; E-mail: workforce@digitalhealth.gov.au.
} 
All Australian governments invest significantly in healthcare for their communities. At the present time, governments are focusing on healthcare transformation seeking new and better ways to provide better access to care in an endeavour to address equity gaps. Nurses and midwives are well placed to deliver this care. They partner and mobilise their services with others across the professions and healthcare industry [4]. Key to this transformation is access to information, recording of information and analysing the information for sound clinical decisions in patient care and treatment planning.

Together, nursing and midwifery form the largest healthcare workforce in Australia and as such, they need to lead as an agile digital healthcare workforce. This may be viewed as an individual or organisational responsibility. However, education providers play a significant role in lessening workforce-related pressures on the healthcare system [1]. Educational institutions must take responsibility for adequately preparing our future healthcare workforces by reviewing and adapting their academic programs and embedding digital capabilities. Industry expectations for work-ready graduates and nursing and midwifery program accreditation criteria $[5,6]$ clearly articulate the need for digital health capabilities training to be embedded within education, ultimately aligning and meeting the demands of the rapidly changing healthcare environment.

The National Nursing and Midwifery Digital Health Capability Framework (the framework) was developed as a practical guide for nurses and midwives to benchmark their current digital health knowledge and skills, and provide a pathway to further their development in this context. Rapid implementation of the framework is supported by the National Digital Health Strategy, which commits to developing a workforce that is able to confidently use digital health technologies and services by 2022 [2].

In the International Year of the Nurse and Midwife, now is the time for the largest workforce in Australia to take the lead in digital health. The purpose of this paper is to provide examples of the potential use of the framework for individual nurses and midwives, organisational managers and education providers.

\section{Methods}

The development of the framework was led by the Australian Digital Health Agency and the Australasian Institute of Digital Health, in collaboration with a governance group comprising representation from the peak nursing and midwifery bodies in Australia, international and consumer representatives. A draft framework was developed based on national and international evidence and further refined in design workshops. Public consultation across the health sector using an online survey, written submissions and consultation sessions gathered feedback on the draft framework in February and March 2020. The final framework was endorsed in June 2020.

\section{The National Nursing and Midwifery Digital Health Capability Framework}

The framework describes the digital health capabilities required of nurses and midwives now and into the future. In summary, the framework outlines the core digital health skills, knowledge, and behaviours required for professional practice across five domains:

- Digital Professionalism: Professional standards are maintained in the digital environment 
- Leadership and Advocacy: Digital health leadership and advocacy supported by clear policy

- Data and Information Quality: Data quality must be present

- Information-enabled Care: Care must be supported by rigorous data analysis and critical appraisal

- Technology: Technology needs to be understood and used appropriately.

Each domain has three sub-domains which sit within the context of nurses' and midwives' roles, workplace settings, and the professional standards that apply to their practice. Finally, each sub-domain is described by four capability statements. The framework is accompanied by a set of resources and case studies that describe potential examples as suggested through the public consultation.

\section{Use of the Framework}

Practical examples of how the framework could be used to advance the digital health knowledge and skills for the nursing and midwifery workforce in Australia are proposed below in three different categories: individual nurses and midwives; organisations; and educational providers. The final subsection provides an international perspective on the framework.

\subsection{Individual Nurses and Midwives}

Primarily, for individuals the framework is intended as a practical guide for nurses and midwives to understand their current digital health knowledge and skills, and provide a pathway to further their professional development. The capability statements, contained within the sub-domains are where users assess their capability level as either formative, intermediate, or proficient. A case study was developed to provide an example of how an individual can use the framework to assess and develop digital health capabilities. Jan is a midwife working in her local public hospital and, with the advent of the COVID-19 pandemic, Jan's workplace has commenced using video-consultations for many antenatal and postnatal visits. Jan has used the framework to find out what additional knowledge and skills she requires to provide care using telehealth (see figure 1). Jan has identified that she has intermediate to proficient skills in most domains, as would be appropriate to her current position. She has noted that she is currently at the foundational level for sub-domains 2.3, 3.3 and 5.2 and, therefore, these are areas where she could expand her knowledge and skills. She can seek professional development opportunities on those topics which can contribute to her annual requirements for continuing professional development. 


\begin{tabular}{|c|c|c|}
\hline & S1. Professional Development & $\begin{array}{l}\text { Jan has recorded her telehealth education in her professional portfolio } \\
\text { for CPD records. }\end{array}$ \\
\hline & 52. Procedural Knowledge & $\begin{array}{l}\text { Jan has accessed her hospital's policies on the use of telehealth } \\
\text { consultations. }\end{array}$ \\
\hline $\begin{array}{l}\text { Digital } \\
\text { Profes: }\end{array}$ & s3. Digital Identity & $\begin{array}{l}\text { Jan ensures her social media posts are professional and maintains an } \\
\text { up-to-date Linkedin work profile. }\end{array}$ \\
\hline & $\begin{array}{l}\text { 51. Patient Digital Health } \\
\text { Advocacy }\end{array}$ & $\begin{array}{l}\text { Jan ensures her patients can use the technology for video- } \\
\text { consultations. }\end{array}$ \\
\hline & $\begin{array}{l}\text { 52. Leadership Within } \\
\text { Organisation }\end{array}$ & $\begin{array}{l}\text { Jan has worked with her colleagues to update their policies to } \\
\text { include telehealth. }\end{array}$ \\
\hline ind & $\begin{array}{l}\text { 53. Digital Leadership in Nursing } \\
\text { and Midwifery Professions }\end{array}$ & $\begin{array}{l}\text { Jan is aware of the Australian College of Midwives' (ACM) work on } \\
\text { national policies for telehealth. }\end{array}$ \\
\hline & S1. Data Capture & $\begin{array}{l}\text { Jan makes sure that she takes accurate and complete notes at the } \\
\text { time of her telehealth session. }\end{array}$ \\
\hline & 52. Data Management & $\begin{array}{l}\text { Jan discusses with her patients what information is being recorded } \\
\text { and who else has access to the data, and for what purposes. }\end{array}$ \\
\hline y & 53. Data Lifecycle & $\begin{array}{l}\text { Jan is unsure about why it is important to always collect and record } \\
\text { data in a structured way. }\end{array}$ \\
\hline & S1. Data Sharing & $\begin{array}{l}\text { Jan makes sure she has authorisation to access patient information } \\
\text { and she shares it securely with others in the patient's care team. }\end{array}$ \\
\hline & $\begin{array}{l}\text { 52. Information Creation } \\
\text { and Use }\end{array}$ & $\begin{array}{l}\text { Jan is accessing articles from various sources to assist her in } \\
\text { telehealth practice. }\end{array}$ \\
\hline Care & 53. Extending Practice & $\begin{array}{l}\text { Jan uses these articles to create resources for her colleagues to help } \\
\text { them with their telehealth sessions. }\end{array}$ \\
\hline & s1. Appropriate Technologies & $\begin{array}{l}\text { Jan recognises when her patients do not have appropriate } \\
\text { technologies to undertake quality telehealth visits and assists } \\
\text { them with access. }\end{array}$ \\
\hline & 52. Digital Health Governance & Jan applies the hospital's governing policies when she is aware of them. \\
\hline $\mathrm{TT}$ & S3. Problem Solving & $\begin{array}{l}\text { Jan is usually able to solve problems with basic technology if they } \\
\text { arise during a telehealth session. }\end{array}$ \\
\hline
\end{tabular}

Figure 1. Use of the framework by an individual midwife: A COVID-19 telehealth case study.

\subsection{Organisations}

The framework has been developed so it can be embedded at a health service or organisational level. The most appropriate nursing and midwifery leaders to undertake this key piece of work are Chief Nursing and Midwifery Information Officers (CNMIOs) as they 'serve as critical links between digital health, organisational change and clinical communities' [7]. Alternatively, a Chief Nursing and Midwifery Officer or similar level nursing and midwifery leader could facilitate this work within a health service context. A flowchart of the steps to assess and improve digital health maturity in an organisation has been developed as a resource to assist with the implementation of this framework (see figure 2).

Prior to commencing the process outlined in the flowchart, organisational governance through the nursing and midwifery professions and commitment to adequate allocation of resources is required. Collaboration between the CNMIO (or equivalent), nursing and midwifery leaders, education teams, digital health team and operational leaders is required, together with engagement and participation from individual nurses and midwives. The flowchart ensures the framework is embedded from an organisational level, commencing with undertaking a subjective assessment of the organisation's level of digital health maturity, the vision and areas for organisational improvement to individual nursing and midwifery staff capability, required resources, and education requirements for staff development. It describes eight discrete but interrelated pieces of work that will need to be undertaken in the order in which they appear. Understanding the outcome of each piece of work is important as this is required to commence the next step. As the flowchart progresses, so will the digital health maturity level of the organisation. 


\section{Steps to assess and improve digital health maturity in your organisation}

1 Subjectively identify your organisation's level of digital health maturity as formative, intermediate or proficient.

2 Create a vision for digital health in your organisation.

3 Use the framework domains and sub-domains to identify where improvement is needed within your organisation as a whole.

4 Ask staff to complete the capability statements to assess their individual capability. Note - this may need to be done anonymously.

5) Collate staff responses and match to your organisation's vision, priorities, and improvement domains.

6) Identify digital health champions from staff responses. Create opportunities for these staff in policy development, education, and other priority areas.

7 Use results from the collated surveys to prioritise education in line with vision.

8 Access/develop and deliver staff education packages.

(9) Reassess organisation's digital health maturity and staff capability.

Figure 2. Use of the framework by an organisation.

The final step is to reassess organisational maturity and staff capability once the other work streams have been completed, ensuring that the flowchart can be revisited to focus on areas for further improvement. Health services that undertake this process and embed the framework will realise a true transition to digital workflows and the associated clinical and professional benefits that support the care provided to communities.

\subsection{Education Providers}

Embedding the digital health capability framework within a nursing and midwifery educational pathway will not be without its challenges. The largest reported obstacle is lack of resources $[8,9]$. However, this is compounded by issues of educator acceptance and knowledge in relation to digital health [8-10]. Successful implementation of any strategy requires recognition by leaders. Nursing and midwifery educational leaders must acknowledge the changing landscape of healthcare delivery. This requires commitment and advocating for nursing and midwifery champions. These champions do not need to be faculty, school or departmental managers, rather enthusiasts with a clear vision and strong commitment to advancing our future workforce.

The champions' focus must be on developing and embedding digital health into the curriculum. This ensures person-centred digital health design, which reflects student learning, clinical partner and accrediting authority requirements. Champions should support and collaborate with industry, ensuring they meet student educational needs. Facilitating all educator learning and timely access to academic digital health technologies (for example, simulated electronic medical and health records, telehealth and mobile health) as well as clinical technologies is a further strategic consideration. Successful embedding and implementation of the framework into curricula is dependent 
on ensuring the champions are visible within the faculty and supported to drive adoption and utility throughout their program [9].

\subsection{International Perspective}

In every corner of the world, nurses and midwives are most commonly the primary point of contact for the assessment, delivery, management and evaluation of care to people across all ages. They are the face of care and as such become the information advocate in a complex, multi-professional, multi-dimensional care structure. In many countries there is a growing realisation that digital health capabilities are central to providing continuity of care as we progress further into the 21 st century. Development of the framework drew upon the National Health Service Health Education England health and care digital capabilities framework [11] for use by nurses, midwives and allied health professionals. In addition, the UK Royal College of Nursing's publication 'Improving Digital Literacy' [12] was helpful. Both these initiatives are helping to transform the delivery of compassionate care through the use of appropriate supportive technologies.

\section{Conclusion}

The National Nursing and Midwifery Digital Health Capability Framework clearly identifies a compelling and easy to follow set of attributes that will ensure all Australian nurses and midwives remain at the forefront of care delivery in the information-intensive working environment. The framework is intended to be used by individual nurses and midwives, organisations and education providers. Future work includes empirical evaluation in each setting and the contextualisation of the framework capabilities to other clinical professions.

\section{References}

[1] Brunner M, et al. An eHealth Capabilities Framework for Graduates and Health Professionals: MixedMethods Study. J Med Internet Res. 2018; 20(5):e10229.

[2] Australian Digital Health Agency. Australia's National Digital Health Strategy: Safe, Seamless and Secure. Sydney: Australian Government; 2017.

[3] Shaw T, Hines M, Kielly-Carroll C. Impact of digital health on the safety and quality of health care. Australian Commission on Safety and Quality in Health Care. Sydney: 2017.

[4] F Hoffmann-La Roche Ltd. Clinical Decision Support, Transforming Complexity into Opportunity: 2020, accessed 31/7/20, www.roche.com/about/business/diagnostics/medical_value/decision-support.htm.

[5] Nursing and Midwifery Board of Australia. Registered nurses standards for practice. Australia: Nursing and Midwifery Board of Australia; 2016.

[6] Nursing and Midwifery Board of Australia. Midwife standards for practice. Australia: Nursing and Midwifery Board of Australia; 2018.

[7] Australian College of Nursing (ACN). Leading digital health transformation: The value of Chief Nursing Information Officer (CNIO) roles - Position Statement. Canberra: ACN; 2019.

[8] Badowski D, et al. Electronic Charting During Simulation: A Descriptive Study. Comput Inform Nurs. 2018; 36(9): 430-437.

[9] Herbert VM, Connors H. Integrating an Academic Electronic Health Record: Challenges and Success Strategies. Comput Inform Nurs. 2016; 34(8): 345-54.

[10] Wilbanks BA, Watts PI, Epps CA. Electronic Health Records in Simulation Education: Literature Review and Synthesis. Simul Healthc. 2018; 13(4): 261-267.

[11] National Health Service / Health Education England (NHS HEE). A Health and Care Digital Capabilities Framework. United Kingdom: NHS HEE; 2017. 
112 L. Woods et al. / Use of the National Nursing and Midwifery Digital Health Capability Framework

[12] Royal College of Nursing (RCN) and NHS HEE. Improving Digital Literacy. United Kingdom: RCN and NHS HEE; 2017. 